\title{
DESENVOLVIMENTO DE COMPETÊNCIAS PROFISSIONAIS: RELATO DA EXPERIÊNCIA UTILIZANDO APRENDIZAGEM BASEADA EM PROJETOS NA DISCIPLINA DE REQUISITOS DE SOFTWARE
}

DEVELOPMENT OF PROFESSIONAL SKILLS: EXPERIENCE REPORT USING PROJECTBASED LEARNING IN THE SOFTWARE REQUIREMENTS SUBJECT

Luis Milene Serrano ${ }^{1}$, Maurício Serrano², André Barros de Sales ${ }^{3}$ DOI: 10.37702/REE2236-0158.v40p76-81.2021

\begin{abstract}
RESUMO
Requisitos de Software é uma disciplina que demanda especial atenção aos conceitos. Por ser mais teórica, torna-se difícil despertar o interesse dos discentes pela disciplina e desenvolver competências profissionais desejadas no mercado, tais como: proatividade, senso crítico e harmonia no trabalho coletivo. Este artigo apresenta um relato experimental sobre o uso da Aprendizagem Baseada em Projetos na disciplina de Requisitos de Software, observando o desenvolvimento dessas competências nos discentes durante dois semestres letivos. A pesquisa envolveu três docentes e cerca de 110 discentes.
\end{abstract}

Palavras-chave: Requisitos de Software; Engenharia de Software; competências profissionais; Aprendizagem Baseada em Projetos.

\begin{abstract}
Software requirements is a discipline that demands special attention to concepts. As it is more theoretical, it becomes difficult to motivate the students in the discipline, and to develop professional skills desired in the market, such as: proactivity, critical sense and harmony in collective work. This article presents an experimental report about the use of Project Based Learning in the Software Requirements discipline, observing the development of these skills in students during two academic semesters. The research involved three professors and almost 110 students.
\end{abstract}

Keywords: Software Requirements; Software Engineering; professional skills; Project Based Learning.

\section{INTRODUÇÃO}

Masson et al. (2012) afirmam que o mundo moderno impõe transformações significativas em diferentes áreas do conhecimento. Essas transformações estão atreladas à própria evolução tecnológica, que atua de forma intensa no cotidiano das pessoas.

No que diz respeito à área de conhecimento das engenharias, é necessário formar engenheiros mais proativos, preocupados com

\footnotetext{
${ }^{1}$ Professora Associada do curso de Engenharia de Software da Faculdade do Gama (FGA) da Universidade de Brasília (UnB), mileneserrano@unb.br

${ }^{2}$ Professor Associado do curso de Engenharia de Software da Faculdade do Gama (FGA) da Universidade de Brasília (UnB), serrano@unb.br

${ }^{3}$ Professor Associado do curso de Engenharia de Software da Faculdade do Gama (FGA) da Universidade de Brasília (UnB), andrebdes@unb.br 
aspectos sociais, humanitários e éticos, além da boa especialização técnica.

Segundo Barbosa e Moura (2014), entre as competências desejadas para esses novos profissionais, destacam-se: conduta ética, iniciativa, criatividade, atitude empreendedora, flexibilidade, autocontrole, comunicação, expressão oral e escrita, entre outras.

Dada a evolução tecnológica atuante no cotidiano das pessoas, impõe-se a necessidade de revisão das matrizes curriculares nas universidades, aproximando o conteúdo dos currículos das tendências de mercado. Autores defendem as Metodologias Ativas (BARBOSA; MOURA, 2014) como forma de lidar com essa demanda, conforme o sugerido pela Aprendizagem Baseada em Projetos (PASCHOAL; SOUZA, 2018). Busca-se maior participação dos discentes, incentivando-os a lidar com problemas reais e a desenvolver competências profissionais que vão além da parte técnica.

O ideal desejado é alinhar as matrizes curriculares a essa realidade, promovendo revisões curriculares nos cursos de graduação. A Resolução n. 5/2016 (RESOLUÇÃO CNE/CES, 2016) - responsável pelas novas Diretrizes Curriculares Nacionais (DCNs) para cursos de graduação na área da Computação, incluindo o curso de Engenharia de Software - estatui que o ensino dessas graduações deve buscar um perfil profissional com viés generalista, humanista e reflexivo, permitindo-lhe compreender e desenvolver suas atividades habilidosamente, além de resolver problemas em vários domínios, como políticos, econômicos, sociais, ambientais e outros.

No intuito de auxiliar a desenvolver competências profissionais nos discentes de Engenharia de Software da UnB, foi realizada uma experiência na disciplina de Requisitos de Software com a abordagem Aprendizagem Baseada em Projetos. Este artigo tem como objetivo relatar o desenvolvimento de algumas competências profissionais nesses discentes.

\section{METODOLOGIA}

Requisitos de Software é uma disciplina obrigatória no curso de Engenharia de Software, posicionada na matriz curricular no $5^{\circ}$ período, com carga de quatro créditos.

A presente pesquisa foi conduzida no primeiro e no segundo semestres de 2019, na disciplina de Requisitos de Software. A turma do primeiro semestre (1/2019) ficou a cargo de dois docentes, ambos doutores em Ciência da Computação. Essa turma contava com 53 discentes, divididos em sete grupos, com sete a nove discentes cada, e apenas um grupo com cinco discentes. Em termos de aprovação, 51 discentes concluíram, dos quais 34 anuíram em participar da pesquisa após ler e assinar o termo de consentimento livre.

A turma do segundo semestre (2/2019) ficou com um docente, doutor em Ciência da Computação. Era composta de 58 discentes, divididos em 10 grupos, sendo oito grupos com seis membros e dois grupos com cinco membros. Em termos de aprovação, os 58 discentes concluíram, dos quais 56 anuíram em participar da pesquisa após ler e assinar o termo de consentimento livre.

Com base na classificação das modalidades de pesquisa descritas em Gil (2010), a presente pesquisa orientou-se por Pesquisa-ação, de cunho exploratório, cujo principal objetivo é conferir uma visão geral, de tipo aproximativo, acerca de determinado fato.

A abordagem da pesquisa é, principalmente, qualitativa, porquanto "a pesquisa qualitativa não se preocupa com representatividade numérica, mas sim com o aprofundamento da compreensão de um grupo social, de uma organização, etc." (GERHARDT; SILVEIRA, 2009). O grupo social analisado constituiu-se de docentes e discentes da Universidade de Brasília da disciplina de Requisitos de Software.

Pesquisa-ação é uma metodologia científica muito indicada para permitir a evolução de algo em estudo de forma iterativa e incremental. No presente projeto, a Pesquisaação permitiu o uso de refinamentos cíclicos na abordagem de Aprendizagem Baseada em 
Projetos, fundando-se nos dados coletados com docentes e discentes via questionários.

Em sua primeira versão, a abordagem orientou-se por módulos, com aulas expositivas, focando em conteúdos teóricos, seguidas de aulas para tirar dúvidas e ainda aulas com apresentações orais, modelo seminário. Cada módulo tinha a perspectiva voltada para um tópico de relevância da área de Requisitos de Software, como técnicas de elicitação e de priorização de requisitos, por exemplo.

Outras evoluções foram aplicadas no período letivo subsequente (2/2019), versão 2.0 da abordagem, como a redução do número de apresentações orais, uma vez que eram ministrados mais de um conteúdo antes da ocorrência de cada seminário. Tais estratégias permitiram uma abordagem multidisciplinar e interdisciplinar mais enfatizada, além de conceder mais tempo para os discentes se prepararem para as avaliações orais. Também foi adicionada na versão 2.0 a avaliação 360 , que consiste numa autoavaliação pelo discente e, em seguida, na avaliação deste sobre os demais integrantes do grupo. Essa avaliação era feita após uma apresentação oral do grupo. Portanto, a presente abordagem contou com duas versões principais: 1.0 e 2.0 .

A Universidade de Brasília, através de uma iniciativa chamada Programa Aprendizagem para o $3^{\circ}$ Milênio (A3M), tem apoiado a pesquisa, a produção de novos conhecimentos e o desenvolvimento de metodologias educacionais inovadoras no processo de ensino e aprendizagem.

Este artigo é um dos resultados do projeto de pesquisa sobre aplicação da abordagem Aprendizagem Baseada em Projetos em algumas disciplinas do curso de Engenharia de Software da Universidade de Brasília. Um outro resultado deste projeto de pesquisa na disciplina de Interação Humano-Computador é apresentado no artigo "Aprendizagem Baseada em Projetos na Disciplina de Interação Humano-Computador" (SALES; SERRANO; SERRANO, 2020).

\section{DISCUSSÃO DOS RESULTADOS}

Foi aplicado aos docentes, em ambos os semestres letivos, um questionário com perguntas de múltipla escolha e discursivas, tendo os docentes como observadores do processo. Percebe-se que os docentes mencionam várias competências profissionais, destacadas nos relatos a seguir:

Professor 1: Os alunos motivaram-se a realizar projetos muito interessantes, explorando todo o conteúdo ministrado em sala de aula, e até mesmo indo além, com a aplicação de conteúdos extras [...] os alunos demonstraram curiosidades, procurando relacionar os conteúdos com suas experiências profissionais [...] Debates proporcionaram uma abrangência ainda maior nos tópicos de interesse e de escopo da disciplina, garantindo ainda correlações interessantes com outras áreas da computação [...] vários debates tratavam questões éticas, de cidadania, acessibilidade, internacionalização e outros aspectos sociais e culturais, o que conferiu uma visão aos alunos que transcende a abordagem de conteúdos técnicos.

Professor 1: [...] a abordagem de Aprendizagem Orientada por Projetos possibilita: (i) despertar nos alunos habilidades de liderança, oratória, proatividade e curiosidade; (ii) participação dos alunos na construção de seus conhecimentos...; (iii) debates com pontos de vista ... de caráter social e cultural, e (iv) ... desenvolver uma visão multidisciplinar sobre a disciplina, pois os projetos demandam esforços em diferentes vertentes, como técnica, gerencial, organizacional ...;

Professor 2: [...] A abordagem desenvolve diversas habilidades nos discentes, como trabalhar em grupo e lidar com os conflitos gerados por trabalhar em grupo [...] permitir que $o$ discente atue como um profissional do mercado exigindo dele uma dedicação regular para desenvolver o projeto durante quase todo o semestre.

Professor 3: [...] existe uma aproximação do docente com os discentes e permite ao discente aplicar o conhecimento do conteúdo num projeto prático, adquirindo uma experiência do mercado dentro de uma disciplina na universidade. A abordagem permite que, ao final do semestre, os discentes entrem em contato com as equipes que desenvolveram comercialmente os projetos para validar os artefatos produzidos na disciplina [...] e algumas vezes publicando esses 
artefatos junto nos sites de empresas conceituadas no mercado de trabalho. Só a validação desses artefatos por essas equipes já produz uma sensação de recompensa nos discentes.

Ao final de cada semestre letivo foi aplicado o questionário aos discentes. Os dados obtidos nas respostas dos participantes, principalmente nas perguntas abertas, são o foco da análise a seguir, sob o ponto de vista dos discentes. Observa-se que estes mencionam várias competências profissionais, destacadas nos relatos a seguir:

Estudante 1: Trabalhar com projetos já existentes e casos de sucesso nos permite ver o que levaram eles a ter sucesso no mercado.

Estudante 2: É uma metodologia que proporciona ao aluno a aplicação dos conhecimentos teóricos para que possam ser mais bem compreendidos. Auxilia também a desenvolver a maturidade de trabalhar em grupo, que é muito importante.

Estudante 3: Os pontos positivos giram em torno da prática ajudando o entendimento da teoria, $o$ ganho que a experiência real proporciona $e o$ incentivo à pesquisa e ao aluno de se esforçar para ir além do visto em sala.

Estudante 4: $O$ método é ótimo e facilita muito o aprendizado de uma disciplina tão grande $e$ complexa.

Estudante 5: Pontos positivos: aprendizagem gradativa, dá para perceber o progresso ao longo do semestre, ajuda a manter o engajamento $e$ estudo da disciplina. O trabalho em grupo ajuda a desenvolver as competências interpessoais. Pontos negativos: nenhum.

Estudante 6: As dinâmicas contribuem para a troca de experiências e de informações entre os grupos e para o aprimoramento individual das soft skills $e$ hard skills; torna o curso de Engenharia de Software mais prático.

Estudante 7: Desenvolve a oratória e aperfeiçoa o comportamento em público, incentivando o trabalho em grupo, a pesquisa e a inovação.

Estudante 8: É bastante trabalhoso, mas o resultado é gratificante.

Estudante 9: Pontos positivos: ajudar ao próximo, respeito, companheirismo, paciência e liderança. Os negativos: noites mal dormidas, estresse, brigas entre integrantes..

Estudante 10: Pontos positivos: trabalho em equipe, surgimento de líderes e gerentes, maior responsabilidade, amadurecimento, apresentar em público.

Estudante 11: A partir desse método, eu fui capaz de desenvolver capacidades em mim, como o controle emocional em apresentações.

Convém salientar algumas particularidades do estudo:

1) turmas relativamente numerosas, em torno de 60 (sessenta) discentes;

2) predominância de discentes homens (mais de $80 \%$ em ambos os semestres), com idades entre 19 e 30 anos, sendo a maioria entre 20 e 22 anos (70,6\%);

$3)$ heterogeneidade entre os discentes, predominando estudantes do quinto período do curso (mais de $40 \%$ em ambos os semestres), mas com a presença de discentes de semestres mais avançados e de profissionais que já atuam em empresas e retornam à academia para atualização/capacitação;

4) discentes com perfil mais voltado para desenvolvimento, sendo um desafio lidar com conteúdos e disciplinas em mais alto nível de abstração, como é o caso da disciplina de Requisitos de Software.

\section{CONSIDERAÇÕES FINAIS}

Dada a era digital, na qual a evolução tecnológica atua de forma intensa nas atividades cotidianas das pessoas, cresce também a necessidade de revisão das matrizes curriculares dos cursos universitários, visando a maior aproximação entre o que é ensinado e as tendências de mercado.

No intuito de despertar competências profissionais nos discentes em Engenharia de Software, da UnB, foram realizadas experiências nas disciplinas de Requisitos de Software e Interação Humano-Computador. Os resultados da pesquisa na disciplina Interação 
Humano-Computador são apresentados no artigo supracitado (SALES; SERRANO; SERRANO, 2020).

Com base nos resultados, a Aprendizagem Baseada em Projetos demonstrou-se bastante pertinente para despertar as competências profissionais. As competências identificadas neste estudo também foram observadas em trabalhos afins. Grotta e Prado (2018) destacam intensificação da parte prática no contexto de programação de computadores. Paschoal e Souza (2018) afirmam que os projetos simulam problemas autênticos, evidenciando competências como autonomia, colaboração e pensamento crítico, nos estudos realizados na disciplina de Gestão de Sistemas de Informação. Ambos os trabalhos aplicam Aprendizagem Baseada em Projetos em disciplinas com perfil mais técnico.

$\mathrm{O}$ relato experimental descrito no presente artigo torna clara a diferença existente entre a experiência em Requisitos de Software e as propostas de Grotta e Prado (2018) e Paschoal e Souza (2018), pois aborda o uso da Aprendizagem Baseada em Projetos numa disciplina de conteúdos mais teóricos, conceituais, em nível de abstração mais elevado.

Portanto, torna-se desafiante despertar proatividade e a aproximação com a prática de um profissional de Engenharia de Software. Entretanto, o sucesso conquistado na experiência tem permitido aos docentes ampliar a aplicação dessa abordagem a outras disciplinas do curso de Engenharia de Software, como em Interação Humano-Computador, por exemplo. Conclui-se que a abordagem proposta é generalista o suficiente para atender disciplinas com perfis similares a Requisitos de Software.

Por fim, entre as limitações da presente pesquisa, destacam-se: i) a não consideração de aspectos sociais no processo de aprendizagem, os quais podem gerar, por exemplo, lacunas cognitivas entre os discentes; e ii) o uso da abordagem em contexto disciplinar, atrelado às avaliações, resumindo a avaliação do aprendizado do discente em uma única nota, ao concluir a disciplina. Tais aspectos serão objeto de estudo nos próximos ciclos de refinamento da abordagem.

\section{REFERÊNCIAS}

BARBOSA, E. F.; MOURA, D. G. Metodologias Ativas de Aprendizagem no Ensino de Engenharia. Int. Conf. on Eng. and Technology Education, Egito, v. 13, 2014.

GERHARDT, D T.; SILVEIRA, D. T. Métodos de Pesquisa. Universidade Aberta do Brasil UAB/UFRGS e Curso de Graduação Tecnológica - Planejamento e Gestão para o Desenvolvimento Rural da SEAD/UFRGS. Porto Alegre: Editora da UFRGS, 2009.

GIL, A. Como elaborar projetos de pesquisa. São Paulo: Atlas, 2010.

GROTTA, A.; PRADO, E. P. V. Um ensaio sobre a Experiência Educacional na Programação de Computadores: a abordagem tradicional versus a aprendizagem baseada em projetos. Anais... XXVI Workshop sobre Educação em Computação (WEI), 26. ISSN 2595-6175, 2018.

MASSON, T. J. et al. Metodologia de Ensino: Aprendizagem baseada em Projetos (PBL). Anais... XL Congresso Brasileiro de Educação em Engenharia (COBENGE), Belém - PA, 2012.

PASCHOAL, L. N.; SOUZA, S. do R. S. Uma experiência sobre a Aplicação de Aprendizagem Baseada em Projetos com Revisão por Pares no Ensino de Gestão de Sistemas de Informação. Anais... XXVI Workshop sobre Educação em Computação (WEI), 26. ISSN 2595-6175, 2018.

RESOLUÇÃO CNE/CES 5/2016. Diretrizes Curriculares dos Cursos de Bacharelado em Ciência da Computação, Engenharia de Computação, Engenharia de Software e Sistemas de Informação e dos Cursos de Licenciatura em Computação. Ministério da Educação-SESU. Diário Oficial da União, Brasília, Seção 1, p. 22-24, 2016.

SALES, A. B. de; SERRANO, M.; SERRANO, M. Aprendizagem Baseada em Projetos na 
Disciplina de Interação Humano-Computador.

RISTI. Revista Ibérica de Sistemas e

Tecnologias de Informação, v. 37, ISSN

1646-9895, 2020.

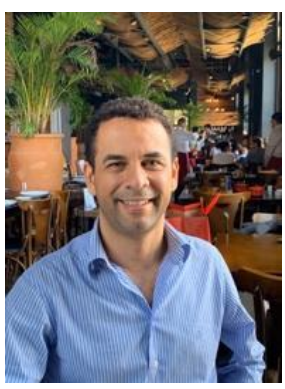

\section{DADOS BIOGRÁFICOS DOS AUTORES}

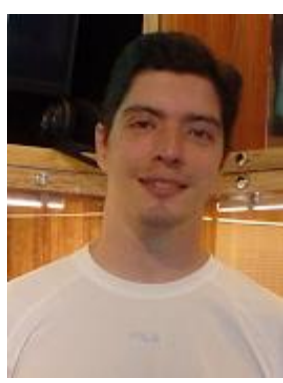

André Barros de Sales - Graduado em Tecnologia em Processamento de Dados pelo Instituto Unificado de Ensino Superior Objetivo em 1993, mestre em Ciência da Computação pela Universidade Federal de Santa Catarina (2000) e doutor em Ciência da Computação pela Université Paul Sabatier, em Toulouse, França, em 2004. Atua como professor associado na Faculdade de Gama da Universidade de Brasília (UnB) desde 2008. ORCID: https://orcid.org/0000-0002-1728-6063.

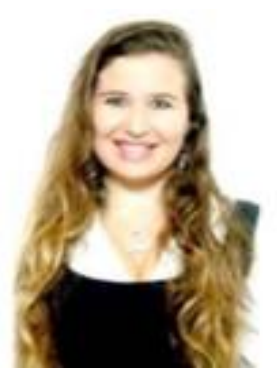

Maurício Serrano - Graduado em Engenharia de Computação pela Universidade Federal de São Carlos (2001), mestre em Ciência da Computação (ênfase em Banco de Dados) pela Universidade Federal de São Carlos (2003), e doutor em Informática (ênfase em Engenharia de Software) pela Pontifícia Universidade Católica do Rio de Janeiro (2011), com um período de um ano na University of Toronto (2009), Toronto, Canadá. Atua como professor adjunto na Faculdade de Gama da Universidade de Brasília (UnB) desde 2012. ORCID: https://orcid.org/0000-00030250-5881.

Milene Serrano - Graduada em Engenharia de Computação pela Universidade Federal de São Carlos (2001), mestre em Ciência da Computação (ênfase em Engenharia de Software) pela Universidade Federal de São Carlos (2003), e doutora em Informática (ênfase em Engenharia de Software) pela Pontifícia Universidade Católica do Rio de Janeiro (2011), com um período de um ano na University of Toronto (2009), Toronto, Canadá. Atua como professora adjunta na Faculdade de Gama da Universidade de Brasília (UnB) desde 2012. ORCID: https://orcid.org/0000-0001-8051-4148. 